\title{
INNOVATIVE RESPONSES FOR PREVENTING HIV TRANSMISSION: THE PROTECTIVE VALUE OF POPULATION-WIDE INTERRUPTIONS OF RISK ACTIVITY
}

\author{
Justin O Parkhurst, BSE, MPhil (Oxford), DPhil (Oxford) \\ Health Policy Unit, London School of Hygiene and Tropical Medicine, Keepel Street, London, UK
}

Alan Whiteside, $M A, D E c o n$

Director, HEARD (Health Economics and HIVIAIDS Research Division), University of KwaZulu-Natal, Durban

\begin{abstract}
Concurrent partnering contributes to high HIV prevalence. This is in part due to the natural history of the virus. After transmission, an individual's viral load spikes in a period of 'acute infection' during which they are highly infectious. ${ }^{12}$ Models estimate that around $10-45 \%$ of HIV acquisition arises from sex with an individual in the acute infection period. ${ }^{3}$
\end{abstract}

If everyone in a population abstained from high-risk sex for a given period of time, in theory the viral loads of all recent seroconverters should pass through the acute infection period. When risk behaviour resumed there would be almost no individuals in the high-viraemic phase, thereby reducing infectivity, and HIV incidence would fall. Recurring population-wide shifts in risk behaviour are not unheard of. Many, in fact, occur as part of existing religious observances. The month of Ramadan in Muslim communities is perhaps one of the most obvious cases. Ramadan sees significant behaviour changes. In addition to fasting from sunrise to sunset, observant individuals abstain from coitus during daylight hours. ${ }^{4}$ There is anecdotal evidence that risky sexual behaviours are also significantly reduced over this period. In Indonesia, for instance, it was reported that research with sex workers was not possible during Ramadan because people 'abstained from sex from one end of the month to the other ... Many sex workers returned to home villages during this time. ${ }^{15}$

This article argues that a population-wide interruption of risk behaviour for a set period of time could reduce HIV incidence and make a significant contribution to prevention efforts. It calls for mathematical modelling of periodic risk behaviour interruptions, as well as encouragement of policy interventions to develop campaigns of this nature. A policy response, such as a 'safe sex/no sex' campaign in a cohesive population, deserves serious consideration as an HIV prevention intervention. In some contexts, periods of abstinence from risk behaviour could also be linked to existing religious practices to provide policy options.

\section{THE ARGUMENT}

There are scientific reasons to believe that population-wide periods of risk reduction could be effective. Additionally there is evidence to suggest that sexual behaviours, including periods of abstinence, driven by religious reasons, may have kept the prevalence low in Muslim countries. According to UNAIDS only one country in North Africa and the Middle East region (Sudan) had an HIV prevalence over $0.2 \%$. In South and SouthEast Asia, predominantly Muslim countries such as $\mathrm{Pa}$ kistan, Bangladesh and Indonesia show similarly low HIV prevalences, typically below $0.2 \% .{ }^{6}$ There are serious challenges in attributing cause, however. The practice of male circumcision is near universal, and is highly protective against men acquiring HIV. ${ }^{7-9}$ While Islam permits polygamy, it prohibits sex outside marriage and discourages the consumption of alcohol and homosexual sex. All these factors may help explain the lower levels of seroprevalence in countries with large Muslim populations. ${ }^{10}$ Norms and patterns of sexual behaviour may also be quite different in observant Muslim communities compared with other groups. Indonesia, for instance, has a low national prevalence rate, estimated to only be around $0.2 \%$, but Papua province has a majority Christian population and an HIV prevalence of $2.4 \%$, over 10 times the national rate. ${ }^{11}$

There are, however, cases where HIV prevalence appears to be unusually low in Muslim areas, even given high levels of risk activity. In Dhaka, Bangladesh, for instance, HIV prevalence apparently remains low despite common risk behaviours of injection drug use and commercial sex. ${ }^{12}$ So while confounding makes it 
hard to attribute the protection derived from Ramadan practices of abstinence, there is scientific plausibility for considering it as an intervention.

A potential intervention would be an aggressive national campaign to ensure that everyone who is sexually active in a population either commit to $100 \%$ condom use or refrain for sexual intercourse over a period of a month or longer. This would be a national campaign with buy-in from leadership at every level, from the President (or King) through church and business down to local community leaders. It could be trialled best in small homogeneous populations, and indeed the National Emergency Response Council on HIV/AIDS (NERCHA) in Swaziland has been considering it (personal communication with author AW). There is also evidence from Mozambique that a 2-month 'cooling off' period during which people would abstain from starting any new sexual relationships would be feasible and acceptable. ${ }^{13}$

\section{TESTING AND VALIDATION}

Avenues can be explored to test or validate the idea that population-wide interruptions in risk behaviour would slow the spread of HIV. On a theoretical level, ideally we feel that this should be further explored through mathematical modelling and estimation exercises. Such exercises could predict how a population-wide abstinence campaign might reduce infections, both in the month of abstinence and over the course of a year through reduction in average viral loads when risk activity resumes. However, models may require some additional survey data to inform their parameters.

In practice, an experimental trial would be impossible and unethical (abstinence is known to be protective on its own), nor would it be feasible to control some groups when such a wide-scale mobilisation effort might be needed to promote the behaviour change. However, discussions are under way to actually attempt interruptions in risk behaviour in this manner, and these must be observed with sufficient evaluation research to be built in. Risk behaviours can be assessed before, during and after the intervention period to assess the impact they may have had. This can be done with surveys as well as in-depth investigation of particular groups to help avoid respondent bias. A campaign for a month of 'safe sex/no sex' would also produce easily verifiable data with regard to adherence, evidenced in the number of births occurring nine months after the campaign. Finally, in theory, the average HIV viral load in the population could also be monitored before, during and after the period of abstinence to see how much it impacted on infectiousness, and to get better estimates of effectiveness in practice over modelling efficacy calculations. However, this might require very large sample sizes to show significant results.

\section{DISCUSSION}

A population-wide 'month off' from risk behaviour may help to interrupt the spread of HIV by allowing the acute infection period to pass and the HIV viral load to fall before risk activity is resumed. The month of Ramadan may provide one example of this that has unknowingly been protective for Muslim societies.

We investigated whether there were other opportunities for abstinence from particular practices similar to Ramadan through a review of major world religions. We did not find examples of sustained populationwide abstinence from sexual activity outside of Islamic societies. Small groups might do so, however, such as the Marange Apostolic sect in Zimbabwe's Manicaland, who were found to abstain from sex during Passover (and also found to have lower prevalence of HIV than surrounding populations). ${ }^{14,15}$ However, many religions do incorporate some form of abstinence or asceticism - whether it is the Christian Lenten restrictions for 40 days ${ }^{4}$ the Hindu Brahmacharya practices (where some young men restrict sexual activity ${ }^{16}$ ), or Buddhist general notions of self-restraint including life-long dietary restrictions. What is critical about periods such as Lent and Ramadan, however, is that they provide clear, extended time periods into which a campaign promoting abstinence from sexual risk behaviour might be incorporated.

While converting people to a religion is not a reasonable public health strategy, these insights do raise the possibility of campaigns to regularly, if only temporarily, reduce risk behaviour across a population. The World Health Organization, for instance, has promoted 'tobacco-free' days. ${ }^{17}$ In this vein, key HIV risk behaviours can be targeted in populations. A 'safe sex/no sex' campaign for a limited period of time may be a reasonable public health intervention strategy to attempt in some settings.

In hyper-epidemic countries in particular, policy makers, populations and politicians are open to new ideas to address the epidemic. Prevalence rates and incidence rates are at unacceptably high levels and to be successful interventions take time and require long-term behaviour change. The 'safe sex/no sex' campaign has the advantage of requiring a one-off short-term adaption, being relatively cheap, having nation-building qualities, and not carrying stigma. Finally, many elements can be easily monitored.

While universal permanent abstinence from sex work may be impossible to achieve, a month of 'no commercial sex' or 'no new partners' might be more possible in some populations in which sex work appears to be a driving influence on spread (mining communities in southern Africa, for instance ${ }^{18}$ ). Permanent monogamy may be a challenging long-term goal for some, but a 
'month of monogamy' might be a useful starting point. It has rarely been attempted to put such ideas into practice, but they may reap significant benefits for HIV prevention.

\section{REFERENCES}

1. Chin J. The AIDS Pandemic: The Collision of Epidemiology with Political Correctness. Oxford: Radcliffe Publishing, 2007.

2. Halperin DT, Epstein H. Concurrent sexual partnerships help to explain Africa's high HIV prevalence: implications for prevention. Lancet 2004; 364: 4-6.

3. Wawer MJ, Gray RH, Sewankambo NK, et al. Rates of HIV-1 transmission per coital act, by stage of HIV-1 infection, in Rakai, Uganda. J Infect Dis 2005; 191: 1403-1409.

4. Ryan F. The Sacred Art of Fasting: Preparing to Practice. Woodstock, VT: SkyLight Paths Publishing, 2005

5. Pisani E. The Wisdom of Whores: Bureaucrats, Brothels, and the Business of AIDS. London: Granta Books, 2008

6. UNAIDS. Report on the Global HIV/AIDS Epidemic. Geneva: UNAIDS, 2008.

7. Gray RH, Kigozi $G$, Serwadda D, et al. Male circumcision for HIV prevention in men in Rakai, Uganda: a randomised trial. Lancet 2007: 369: 657-666.

8. Bailey RC, Moses S, Parker CB, et al. Male circumcision for HIV prevention in young men in Kisumu, Kenya: a randomised controlled trial. Lancet 2007; 369: 643-656.
9. Auvert B, Taljaard D, Lagarde E, Sobngwi-Tambekou J, Sitta R, Puren A. Randomized, controlled intervention trial of male circumcision for reduction of HIV infection risk: the ANRS 1265 trial. PLoS Med 2005; 2: 0001-0011.

10. Gray P. HIV and Islam: is HIV prevalence lower among Muslims? Soc Sci Med 2004; 58: 1751-1756.

11. Statistics Indonesia (BPS), ORC Macro. Indonesia Demographic and Health Survey 2007. Calverton, Md: BPS and Macro International, 2008.

12. Foss $A M$, Watts $C_{\text {, }}$ Vickerman $P$, et al. Could the CARE-SHAKTI intervention for injecting drug users be maintaining the low HIV prevalence in Dhaka, Bangladesh? Addiction 2006; 102: 114-125.

13. Halperin D, Cipriano E, Senda R, et al. A two-month national 'cooling-off' period? Acceptability of an intensive behavior change campaign to reduce acute HIV infection in Mozambique. Presentation at the HIV Acute Infection Meeting, Boston, 22 - 23 September, 2009.

14. Gregson S, Ndlovu J, Mlilo M, Dauka E. Fluctuations in sexual activity, the validity of sexual behaviour estimates for short time-intervals, and HIV intervention evaluation in rural Zimbabwe. J Sex Res 2001; 2: 180-181.

15. Gregson S, Zhuwau T, Anderson RM, Chandiwana SK. Apostles and zionists: the influence of religion on demographic change in rural Zimbabwe. Popul Stud 1999; 53: 179-193.

16. Alter JS. Celibacy, sexuality, and the transformation of gender into nationalism in North India. The Journal of Asian Studies 1994: 53: 45-66.

17. World Health Organization. Showing the Truth, Saving Lives: The Case for Pictoral Health Warnings. Geneva: WHO, 2009.

18. Campbell C. 'Letting Them Die': Why HIV/AIDS Prevention Programmes Fail. Oxford: James Currey, 2003.

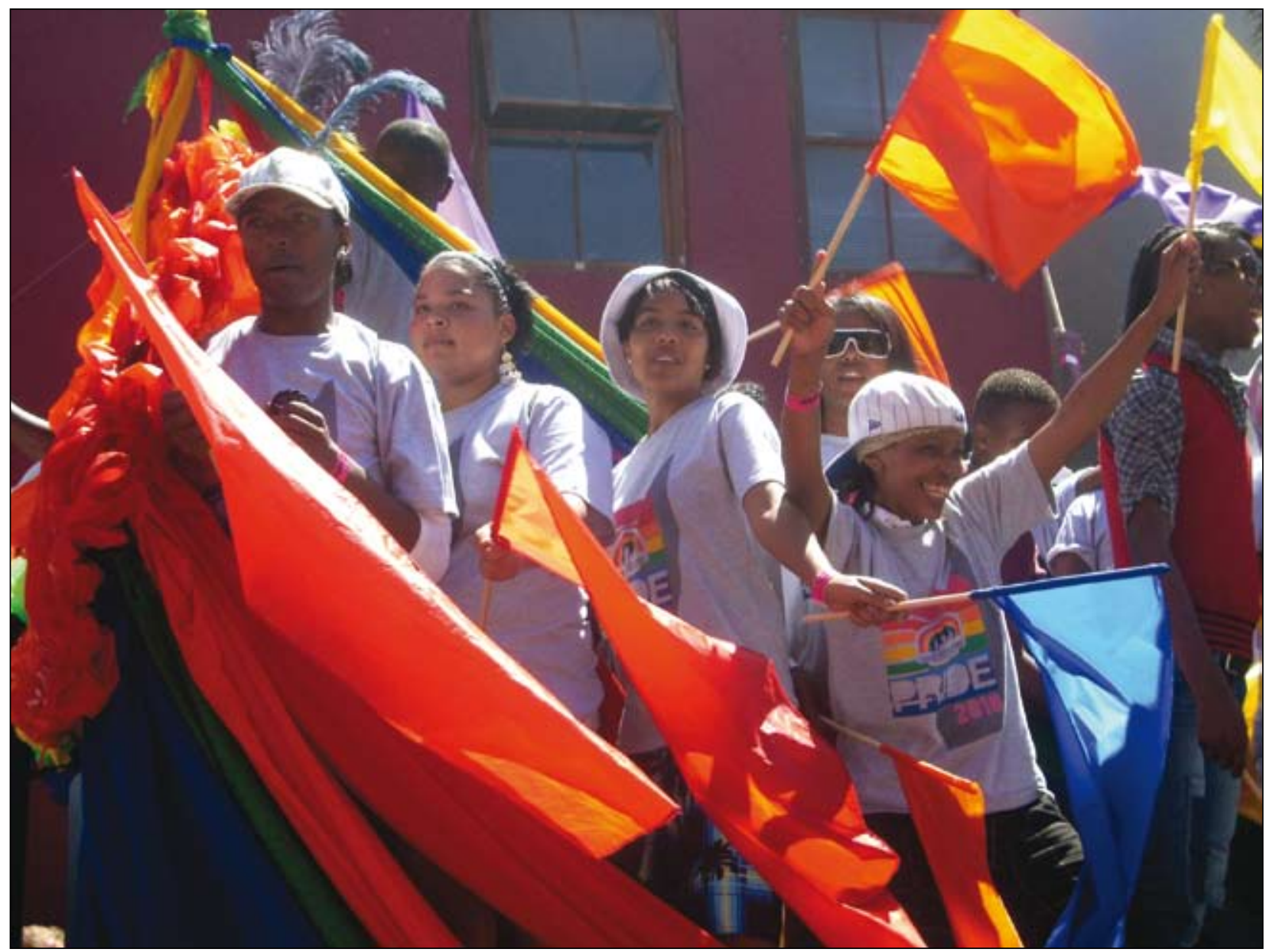

